\title{
The Effect of Polystyrene on the Crystallization of Poly(3-hydroxybutyrate)
}

\author{
Renate Maria Ramos Wellen ${ }^{a *}$, Eduardo Luís Canedo ${ }^{a}$, Camila Augusta Ventura Lima ${ }^{b}$, \\ Inaldo Cesar Araújo Júnior ${ }^{b}$, Yêda Medeiros Bastos de Almeida ${ }^{b}$, Marcelo Silveira Rabello
}

\author{
${ }^{a}$ Pernambuco Institute of Technology, CEP 50740-540, Recife, PE, Brazil \\ ${ }^{b}$ Department of Chemical Engineering, Federal University of Pernambuco, \\ CEP 50740-521, Recife, PE, Brazil \\ ${ }^{c}$ Department of Materials Engineering, Federal University of Campina Grande, \\ CEP 58429-140, Campina Grande, PB, Brazil
}

Received: September 20, 2013; Revised: January 16, 2015

\begin{abstract}
Mechanical properties, morphology and nonisothermal crystallization of poly(3-hydroxybutyrate) (PHB) and blends of PHB and polystyrene (PS) were studied by tensile tests, scanning electron microscopy (SEM) and differential scanning calorimetry (DSC). A two-phase structure composed by a PHB matrix and nearly spherical particles of PS was clearly noticed in SEM images. The presence of small amounts $(0.5 \%$ to $3 \%)$ of amorphous PS affected the crystallinity of PHB, being more evident when high cooling rates were applied. The kinetics of nonisothermal crystallization was modeled according to Ozawa equation. The dependence of Ozawa parameters on temperature followed the same trend for PHB and PHB/PS blends; model parameters were found to be lower for the blends than for the neat PHB.
\end{abstract}

Keywords: poly(3-hydroxybutyrate) (PHB), polystyrene (PS), blends, nonisothermal crystallization kinetics, Ozawa model

\section{Introduction}

A current concern of the scientific community and the society in general is the environment preservation and other ecological issues. Committed with this cause, polymer researchers have sought alternatives to deal with synthetic plastic waste by directing their research to the study of development and use of polymers obtained from renewable sources, such as bacterial fermentation and sugar cane. Some of these biopolymers, like poly (3-hydroxybutyrate) (PHB), are semi crystalline, i.e., they have amorphous disordered phase, amorphous ordered phase and crystalline phase. Their macromolecular arrangement depends on processing parameters and configuration of the chemical structure, hence, the understanding of the morphology and its effects in mechanical properties is an obvious issue ${ }^{1-5}$.

PHB is biodegradable and biocompatible thermoplastic and has been used in many products, including packing and health care industries, drugs release devices, prosthesis, and threads for suture. A usual difficulty when dealing with this polymer, however, is that it is rather unstable during processing, mainly due to a short processing window between melting and degradation temperatures. In addition PHB is highly crystalline that, together with the high glass transition temperature, results in a very fragile material that limits its applications. On going research, intended on establishing its properties, and optimizing its processing conditions is reported in the literature ${ }^{5-7}$.

*e-mail: wellen.renate@gmail.br
In previous work ${ }^{8}$ the authors reported that the addition of small amounts (ca., 1\%) of polystyrene to PET reduced the cold crystallization rate of PET, with no effects on mechanical properties. This article follows the same trend of blending polystyrene to a crystallizable polymer. In an effort to improve the PHB properties, processability and, in addition, to understand its crystallization behavior, blends of PHB with small amounts of PS were produced by melting blending and the melt crystallization parameters, morphology and tensile properties were investigated.

\section{Experimental}

\subsection{Materials}

Poly (3-hydoxybutyrate) resin used in the present study, with a weight-average molecular weight $M_{W}=340 \mathrm{kDa}$ and a melt flow rate (ASTM D-1238) ${ }^{9} \mathrm{MFR}=26 \mathrm{dg} / \mathrm{min}$ $\left(2.16 \mathrm{~kg} / 190{ }^{\circ} \mathrm{C}\right)$, was supplied by PHB Industrial SA (Brazil). The polystyrene was a standard injection grade material, Styron 649D, from Dow Chemical.

\subsection{Methods}

PHB/PS blends with PS content ranging between 0.5 and $3 \mathrm{wt} \%$ were compounded in a Haake Rheomix 3000 internal mixer fitted with high-intensity ("roller" type) rotors, for $12 \mathrm{~min}$ at $180^{\circ} \mathrm{C}$ and $60 \mathrm{rpm}$; neat PHB was also processed at same conditions to ensure the same thermal 
history. Immediately after mixing, the melt was quenched in iced water to hinder PHB crystallization.

Tensile tests, according to ASTM D- $638^{10}$, were carried out using an Emic Instrument universal testing machine with a crosshead speed of $5 \mathrm{~mm} / \mathrm{min}$; the averages of four runs of each formulation are reported.

Differential scanning calorimetry (DSC) analyses were performed in a Mettler-Toledo STARe System, model DSC1, under nitrogen flux of $50 \mathrm{~mL} / \mathrm{min}$. Samples of approximately $6 \mathrm{mg}$ were heated until fully molten at $178^{\circ} \mathrm{C}$ and kept for 5 minutes at this temperature before cooling. Tests were run at constant rates of heating/cooling of 5, 10, 15 , and $20^{\circ} \mathrm{C} / \mathrm{min}$ (Figure 1).

A JEOL, JSM-6360 scanning electron microscope was used to study the phase morphology of PHB/PS blends, which were cryogenically fractured in liquid nitrogen and the fractured surface was covered with carbon for avoid the accumulation of charges.

\section{Results and Discussion}

Figure 1 shows an example of a DSC scan for $\mathrm{PHB} / 1 \% \mathrm{PS}$ blend heated $/$ cooled at $10^{\circ} \mathrm{C} / \mathrm{min}$, including the temperature program of the experiment. Since PS is a fully amorphous polymer (a fact confirmed by running DSC scans of pure PS) the melting and crystallization processes recorded by DSC were attributed to presence of PHB in the samples. The melting range was $148^{\circ} \mathrm{C}-178^{\circ} \mathrm{C}$, which is consistent with other results from the literature ${ }^{5}$. After melting, the samples were crystallized and the crystallization peak temperatures $\left(T_{\mathrm{c}}\right)$ was in the range of $80{ }^{\circ} \mathrm{C}-110{ }^{\circ} \mathrm{C}$. The values of $\mathrm{T}_{\mathrm{c}}$ were found to be highly dependent on the cooling rate $(\phi=|d T / d t|)$; faster rates leading the crystallization peaks towards lower temperatures, but practically independent of the PS content (Figure 2).

The area under the crystallization peak is related to latent heat of crystallization, $\Delta H_{C}$, which is proportional to crystallinity (crystalline fraction of PHB in the sample). $\Delta H_{C}$ was obtained from the area between the DSC peak output $J(t)$ and a suitable baseline $J_{0}(t)$, according to Equation (1):

$$
\Delta H_{c}=\frac{\int_{t_{1}}^{t_{2}}\left[J\left(t^{\prime}\right)-J_{0}\left(t^{\prime}\right)\right] d t^{\prime}}{m_{S}}
$$

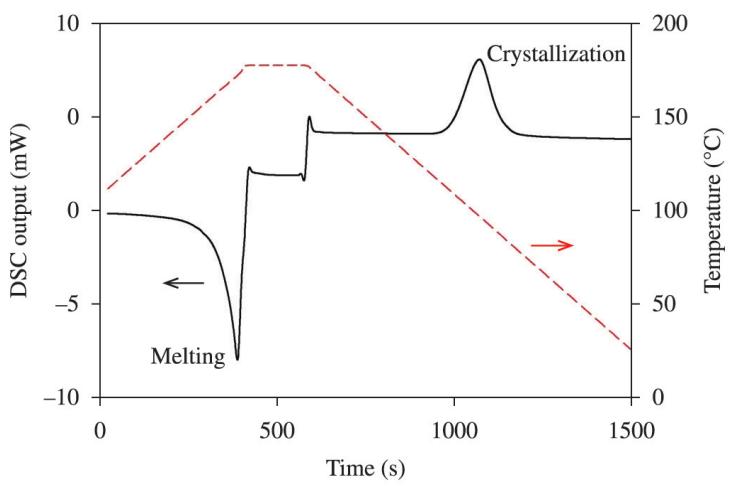

Figure 1. Typical DSC output plot for PHB/PS blend with 1\% PS, heated $/$ cooled at $10^{\circ} \mathrm{C} / \mathrm{min}$. where $t_{1}$ and $t_{2}$ are the onset and end times of the crystallization peak, and $m_{S}$ is the sample mass. Since PS is an amorphous resin, the crystallinity of PHB in a $\mathrm{PHB} / \mathrm{PS}$ blend was estimated from crystallization heat as Equation (2):

$$
X=\frac{\Delta H_{c}}{\left(1-w_{\mathrm{PS}}\right) \Delta H_{m}^{0}\left(T_{c}\right)}
$$

where $w_{\mathrm{PS}}$ is the mass fraction of PS in the blend and $\Delta H_{m}^{0}\left(T_{c}\right)$ is the latent heat of fusion of $100 \%$ crystalline PHB at the temperature of crystallization $T_{C}$. The later is usually known only at the crystalline melting point $T_{M}$. For PHB, a value of $\Delta H_{m}^{0}\left(T_{m}\right)=146 \mathrm{~J} / \mathrm{g}$ was used ${ }^{11}$.

The crystallinities of the neat PHB $\left(\mathrm{X}_{\mathrm{PHB}}\right)$ resin and the PHB/PS $\left(\mathrm{X}_{\mathrm{PHB} / \mathrm{PS}}\right)$ blends were found to be significantly affected by cooling rate, as given in Figure 3 for the case of the blends with $1 \%$ PS (remaining results are not showed here). The general trend towards a decrease in crystallinity with increasing cooling rates can be explained by the decrease in the available time to develop the crystals. At cooling rates lower than $10^{\circ} \mathrm{C} / \mathrm{min}$ the crystallinity of the

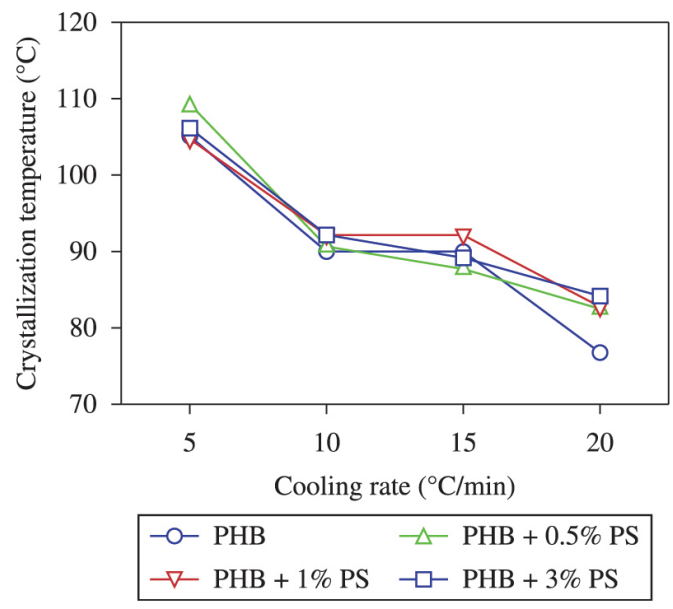

Figure 2. Crystallization peak temperature of PHB and PHB/PS blends as a function of cooling rate.

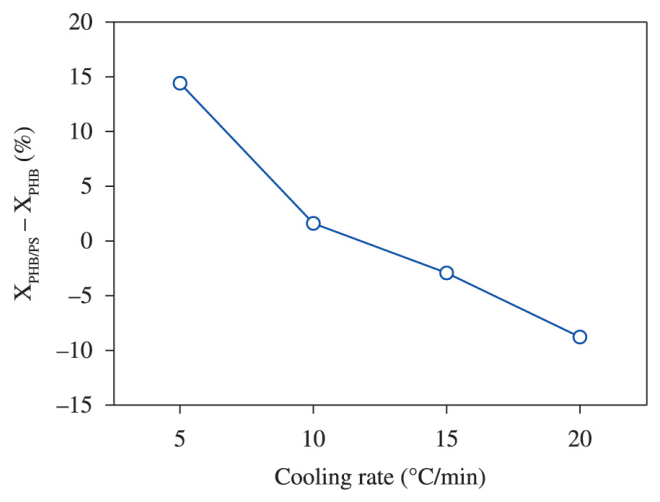

Figure 3. Decrease of PHB crystallinity upon addition of $1 \%$ PS as a function of the cooling rate. The trend seen above was observed with all compositions. 
blends was equal or even higher that the crystallinity neat PHB, which may be caused by the fact that PS particles acted as heterogeneities and promoted the crystallinity ${ }^{3,12}$. However, as the cooling rate increased, the crystallinity of the blend decreases to values lower than those for the neat resin. It is possible that at high cooling rates the chains of PS do not have sufficient time to move outside of crystallization zone, thus hindering the growth of spherulites and contributing to lower the level of crystalinnity ${ }^{13-14}$

The fractional crystallization (or relative crystallinity) during crystallization may be defined as $x=X / X_{\infty}$, where $X$ is the crystallinity developed at time $t$ (or temperature $T$ ) and $X_{\infty}$ is the final crystallinity. The relative crystallinity was estimated by integration of the DSC peak from the onset of the crystallization:

$$
x=\frac{\int_{T_{1}}^{T}\left[J\left(T^{\prime}\right)-J_{0}\left(T^{\prime}\right)\right] d T^{\prime}}{\int_{T_{1}}^{T_{2}}\left[J\left(T^{\prime}\right)-J_{0}\left(T^{\prime}\right)\right] d T^{\prime}}
$$

where $J(T)$ is the DSC output in terms of temperature, $J_{0}(T)$ is the virtual baseline signal during the event, $T_{1}$ and $T_{2}$ are the onset and end temperatures of the crystallization peak, and $T$ is an intermediate temperature, $T_{1} \leq T \leq T_{2}$. The fractional crystallization may be considered as a function

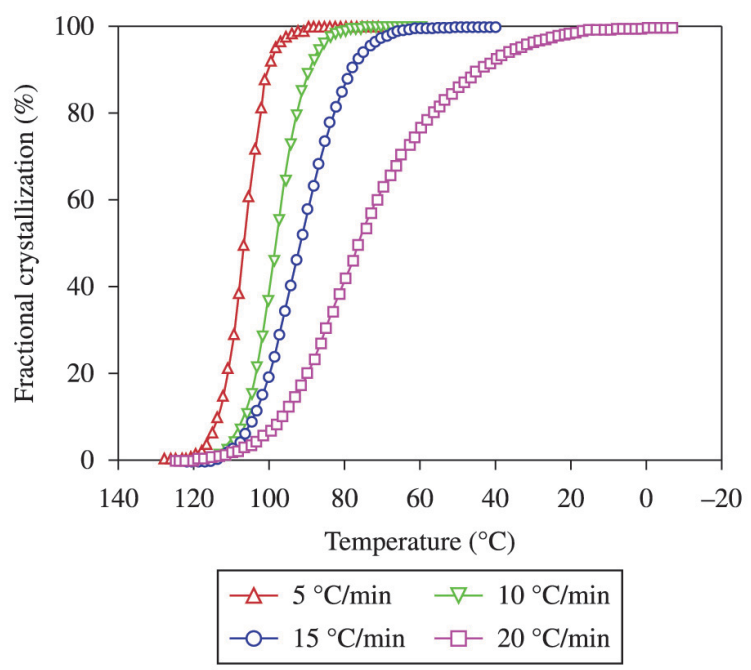

Figure 4. Typical crystallization plot (fractional crystallization vs temperature) for PHB/PS blend with $1 \%$ PS. of either time $(t)$ or temperature $(T)$, since the temperature is a linear function of time at constant heat rate, $T=T_{0}-\phi \mathrm{t}$, where $\phi$ is the cooling rate and $T_{0}$ is the temperature at the starting point of the cooling run.

Figure 4 shows the fractional crystallization for several cooling rates as a function of temperature, for a PHB/PS blend with $1 \%$ PS. In these results a deviation from linearity at the end of crystallization process is observed, which increases with increasing cooling rates. This deviation may be associated with development of thermally unstable crystalline entities and/or crystallization occurring at the impingement zones, and generally originating imperfect crystals of lower crystallinity degree, a phenomenon called secondary crystallization ${ }^{15-17}$. The results agree with the discussion of Figure 3.

Ozawa model ${ }^{18}$ was used to better evaluate the kinetics of crystallization. The model assumes that nonisothermal crystallization is governed by the same mechanism proposed by Avrami ${ }^{19}$ for isothermal crystallization. An interesting feature of Ozawa model is the possibility to compare the results of crystallization during continuous cooling/heating with those obtained by means of the Avrami equation under isothermal conditions. Ozawa model requires a constant rate of temperature change, $\phi=|d T / d t|$, and has been successfully used to study a number of nonisothermal crystallization processes $^{13,15}$. Ozawa kinetic model is given by:

$$
x=1-\exp \left(-k \phi^{-m}\right)
$$

where $x$ is the fractional crystallization, $\phi$ is the cooling rate, and $\kappa$ and $m$ are the Ozawa parameters, which are function of the temperature and depend on nucleation and growth mechanisms. From Equation (4) we obtain:

$$
\ln [-\ln (1-x)]=\ln \kappa-m \ln (\phi)
$$

Consequently, Ozawa model predicts a linear relationship between $\ln [-\ln (1-x)]$ and $\ln \phi$ at constant temperature. Ozawa parameters for the crystallization of PHB and PHB/PS blends with $1 \%$ and $3 \%$ PS were determined at several temperatures between $80{ }^{\circ} \mathrm{C}$ and $110^{\circ} \mathrm{C}$ (Table 1 ).

Figure 5 shows graphically the dependence of the Ozawa parameters with temperature for neat PHB and a blend with $3 \%$ PS. The trend for the two types of samples is similar, but the values for the blends are significantly lower than for the neat polymer. The parameter $\kappa$ also

\begin{tabular}{|c|c|c|c|c|c|c|}
\hline & $110^{\circ} \mathrm{C}$ & $105^{\circ} \mathrm{C}$ & $100^{\circ} \mathrm{C}$ & $95^{\circ} \mathrm{C}$ & $90^{\circ} \mathrm{C}$ & $80^{\circ} \mathrm{C}$ \\
\hline PHB & - & 5.257 & 5.700 & 5.709 & 5.464 & - \\
\hline $\mathrm{PHB}+1 \% \mathrm{PS}$ & 1.881 & - & 4.865 & - & 5.132 & 4.888 \\
\hline $\mathrm{PHB}+3 \% \mathrm{PS}$ & 3.707 & - & 5.091 & - & 4.748 & 4.528 \\
\hline \multicolumn{7}{|c|}{$m$} \\
\hline & $110^{\circ} \mathrm{C}$ & $105^{\circ} \mathrm{C}$ & $100^{\circ} \mathrm{C}$ & $95^{\circ} \mathrm{C}$ & $90^{\circ} \mathrm{C}$ & $80^{\circ} \mathrm{C}$ \\
\hline PHB & - & 3.23 & 2.98 & 2.67 & 2.35 & - \\
\hline $\mathrm{PHB}+1 \% \mathrm{PS}$ & 2.04 & - & 2.43 & - & 2.06 & 1.67 \\
\hline $\mathrm{PHB}+3 \% \mathrm{PS}$ & 3.19 & - & 2.71 & - & 1.97 & 1.49 \\
\hline
\end{tabular}
showed much lower values for the blends and, again, a

Table 1. Kinetic parameters (Ozawa model) for PHB and PHB/PS blends at different temperatures $\ln \kappa$. 

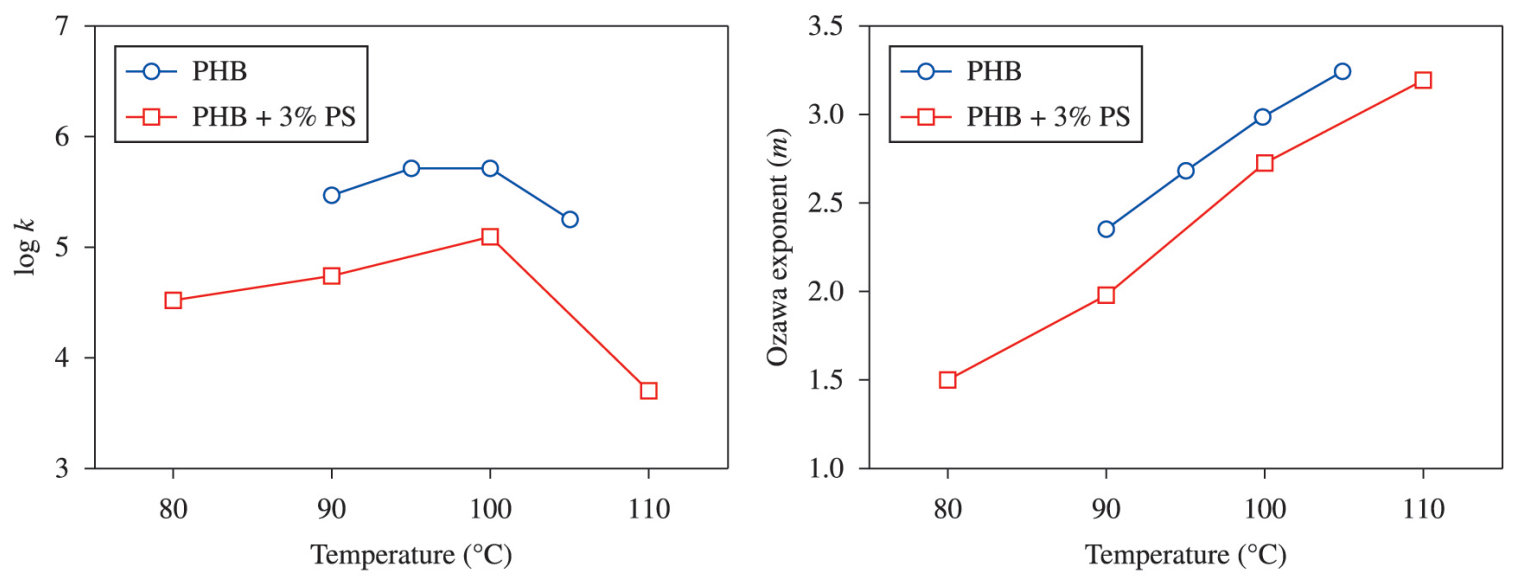

Figure 5. Ozawa parameters, Equation (4), for PHB and a PHB/PS blend with 3\% PS.

Table 2. Mechanical properties of PHB and PHB/PS blends.

\begin{tabular}{cccc}
\hline & PHB & PHB + 0.5\% PS & PHB + 3.0\% PS \\
\hline Elastic modulus (MPa) & $826.3 \pm 24.2$ & $781.4 \pm 33.6$ & $765.3 \pm 32.7$ \\
Tensile strength (MPa) & $33.1 \pm 0.2$ & $34.4 \pm 0.9$ & $33.2 \pm 0.5$ \\
Elongation at break (\%) & $5.7 \pm 0.2$ & $6.5 \pm 0.4$ & $5.8 \pm 0.1$ \\
\hline
\end{tabular}

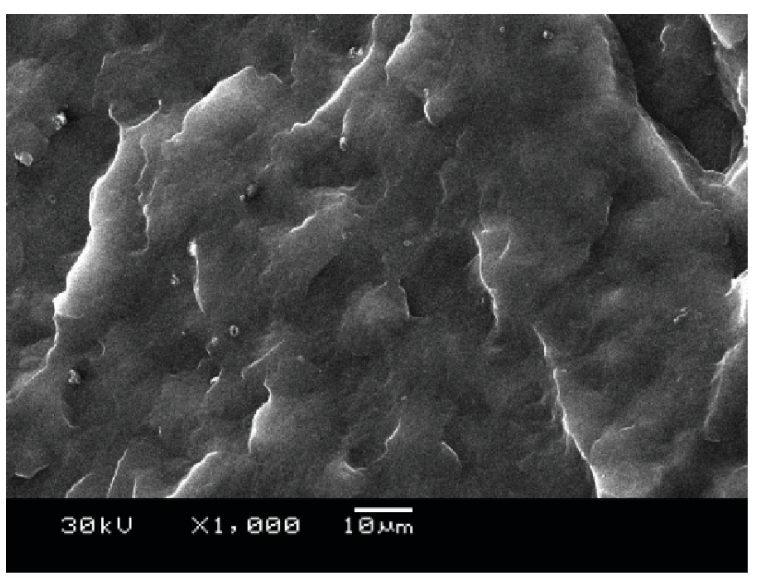

(a)

Figure 6. SEM images of neat PHB (a) and blend with 3\% PS (b).

similar trend with temperature is observed. The lower Ozawa rate parameter $\kappa$ obtained with the blends is related to the presence of PS chains, which act as irregularities at the crystallization border of PHB and, therefore, hinder the crystallization. This is consistent with results previously discussed (Figure 3). The Ozawa exponent $m$ is related to the size and perfection of crystallites; high values of $m$ can be associated to large and stable, more perfect crystallites, whereas lower values of $m$ denote smaller and/or less stable crystals ${ }^{20-22 .}$

Table 2 presents the results of mechanical properties of PHB and the blends with PS. The results are quite

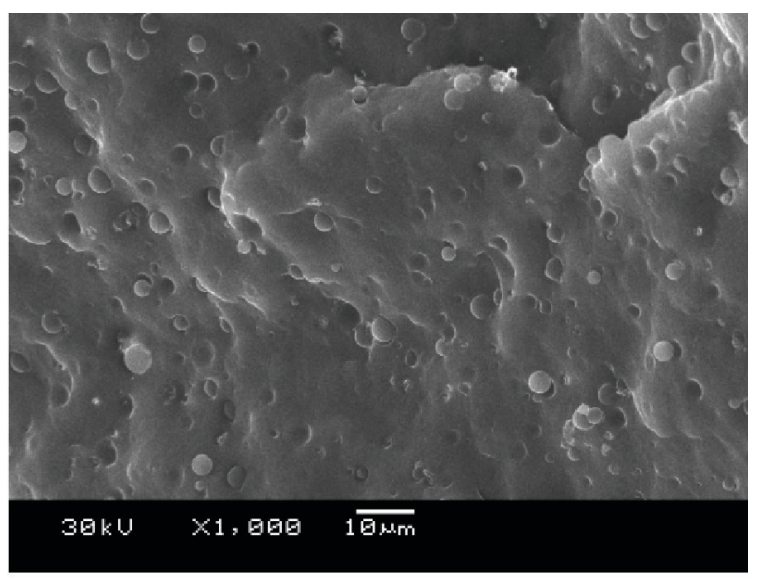

(b)

similar, showing that the presence of small amounts of PS did not cause significant variations in the mechanical properties of PHB, except for the elastic modulus that had a reduction of $8 \%$ for the blend with $3 \%$ PS. Since the degree of crystallinity of PHB did not change much with the presence of PS (Figure 3), the mechanical properties follow the same trend.

The morphology of PHB and its blend with PS were examined by SEM and typical images are shown in Figure 6. A two-phase structure composed by a PHB matrix and nearly spherical particles of PS is clearly noticed. Some PS particles remained attached to the matrix on the fractured surface, 
which may indicate reasonable interfacial interactions between the components.

\section{Conclusions}

Nonisothermal melt crystallization kinetics of PHB and PHB/PS blends with small amounts $(0.5 \%$ to $3 \% \mathrm{wt})$ of amorphous PS was investigated by differential scanning calorimetry (DSC), and the kinetics parameters were determined using the Ozawa model. In all situation cooling rates influenced the mechanisms of PHB crystallization, where higher rates contributed to less stable crystallization process. PHB/PS blends presented two-phase structure composed by a PHB matrix and spherical particles of PS

\section{References}

1. Renstad R, Karlsson S, Albertsson A, Werner P and Westdahl M. Influence of Processing Parameters on the Mass Crystallinity of Poly(3-hydroxybutyrate-co-3-hydroxyvalerate). Polymer International. 1997; 43(3):201-209. http://dx.doi.org/10.1002/ (SICI)1097-0126(199707)43:3<201::AID-PI761>3.0.CO;2-7.

2. Reddy CS, Ghai R, Rashmi and Kalia VC. Polyhydroxyalkanoates: an overview. Bioresource Technology. 2003; 87(2):137-146. http://dx.doi.org/10.1016/S09608524(02)00212-2. PMid:12765352

3. Cimmino S, Iodice P, Martuscelli E and Silvestre C. Poly(3-D(-) hydroxybutyrate)/atactic poly(methylmethacrylate) blends: Morphology, miscibility and crystallization relationships. ThermochimicaActa. 1998;321(1-2):89-98. http://dx.doi. org/10.1016/S0040-6031(98)00444-4.

4. El-Hadi A, Schnabel R, Straube E, Müller G and Henning S. Correlation between degree of crystallinity, morphology, glass temperature, mechanical properties and biodegradation of poly (3-hydroxyalkanoate) PHAs and their blends. Polymer Testing. 2002; 21(6):665-674. http://dx.doi.org/10.1016/S01429418(01)00142-8.

5. Wellen RMR, Rabello MS, Fechine GJM and Canedo EL. The melting behaviour of poly(3-hydroxybutyrate) by DSC. Reproducibility study. Polymer Testing. 2013; 32(2):215-220. http://dx.doi.org/10.1016/j.polymertesting.2012.11.001.

6. Avella M, Martuscelli E and Greco P. Crystallization behaviour of poly(ethylene oxide) from poly(3-hydroxybutyrate)/ poly(ethylene oxide) blends: phase structuring, morphology and thermal behaviour. Polymer. 1991; 32(9):1647-1653. http:// dx.doi.org/10.1016/0032-3861(91)90401-4.

7. An Y, Dong L, Xing P, Zhuang Y, Mo Z and Feng Z. Crystallization kinetics and morphology of poly $(\beta$ hydroxybutyrate) and poly(vinyl acetate) blends. European Polymer Journal. 1997; 33(9):1449-1452. http://dx.doi. org/10.1016/S0014-3057(97)00015-3.

8. Wellen RMR and Rabello MS. Redução da velocidade de cristalização a frio do PET napresença de poliestireno. Polímeros: Ciências e Tecnologia. 2007; 17(2):113-122.

9. American Society for Testing and Materials - ASTM. ASTM D638-03: standard test method for tensile properties of plastics. West Conshohocken; 2003.

10. American Society for Testing and Materials - ASTM. ASTM D1238-04: standard test method for melt flow rates of thermoplastics by extrusion plastometer. West Conshohocken; 2004.

11. Barham PJ, Keller A, Otun EL and Holmes PA. Crystallization and morphology of a bacterial thermoplastic: poly-3- which were observed by SEM images. The mechanical behaviour was also investigated and the results showed that the presence of PS had little influence in PHB tensile properties.

\section{Acknowledgements}

The authors wish to thanks Prof. Agnelli (UFSCar, São Carlos, SP, Brazil) for compounding de PHB/PS blends, PHB Industrial SA (Brazil) for the PHB, Mettler-Toledo (Brazil) for the DSC scans. The authors also thank Conselho Nacional de DesenvolvimentoCientifico e Tecnológico (CNPq/Brazil) and Fundação de Amparo à Ciência e Tecnologia do Estado de Pernambuco (FACEPE/Brazil) for financial support.

hydroxybutyrate. Journal of Materials Science. 1984; 19(9):2781-2794. http://dx.doi.org/10.1007/BF01026954.

12. Liu J, Yang L, Wang Z, Dong S and Liu J. Effect of nucleating agents on the crystallization of poly(3-hydroxybutyrate-co-3hydroxyvalerate). Journal of Applied Polymer Science. 2002; 86(9):2145-2152. http://dx.doi.org/10.1002/app.11023.

13. Ziaee Z and Supaphol P. Non-isothermal melt- and coldcrystallization kinetics of poly(3-hydroxybutyrate). Polymer Testing. 2006; 25(6):807-818. http://dx.doi.org/10.1016/j. polymertesting.2006.04.009.

14. Chen C, Fei B, Peng S, Zhuang Y, Dong L and Feng Z. Nonisothermal crystallization and melting behavior of poly(3hydroxybutyrate) and maleated poly(3-hydroxybutyrate). European Polymer Journal. 2002; 38(8):1663-1670. http:// dx.doi.org/10.1016/S0014-3057(02)00046-0.

15. Hwang H, Jung $\mathrm{C}$ and Lee W. Crystallinity and thermal characterization of $\mathrm{P}(\mathrm{HB}-\mathrm{HV}) / \mathrm{PVAc}$ blend. European Polymer Journal. 1998; 34(7):949-953. http://dx.doi.org/10.1016/ S0014-3057(97)00215-2.

16. Kong X, Yang X, Li G, Zhao X, Zhou E and Ma D. Nonisothermal crystallization kinetics: poly(ethylene terephthalate)-poly(ethylene oxide) segmented copolymer and poly(ethylene oxide) homopolymer. European Polymer Journal. 2001; 37(9):1855-1862. http://dx.doi.org/10.1016/ S0014-3057(01)00046-5.

17. Chen C, Fei B, Peng S, ZhuangY, DongL and FengZ. Nonisothermal crystallization and melting behavior of poly(3hydroxybutyrate) and maleated poly(3-hydroxybutyrate). European Polymer Journal. 2002; 38(8):1663-1670. http:// dx.doi.org/10.1016/S0014-3057(02)00046-0.

18. Ozawa T. Kinetics of non-isothermal crystallization. Polymer. 1971; 12(3):150-158. http://dx.doi.org/10.1016/00323861(71)90041-3.

19. Avrami M. Kinetics of phase change. I General theory. The Journal of Chemical Physics. 1939; 7(12):1103-1112. http:// dx.doi.org/10.1063/1.1750380.

20. Run M, Yao C and Wang Y. Morphology, isothermal and non-isothermal crystallization kinetics of poly(methylene terephthalate). European Polymer Journal. 2006; 42(3):655662. http://dx.doi.org/10.1016/j.eurpolymj.2005.08.010.

21. Liu T, Mo Z and Zhang H. Nonisothermal crystallization behavior of a novel poly(aryl ether ketone): PEDEKmK. Journal of Applied Polymer Science. 1998; 67(5):815-821. http://dx.doi. org/10.1002/(SICI)1097-4628(19980131)67:5<815::AIDAPP6>3.0.CO;2-W.

22. Van Krevelen DW. Properties of polymers. 3rd ed. Amsterdam: Elsevier; 1990. p. 109-118. 